\title{
Buckle up! Endoscopic retrieval of unusual foreign objects
}

\author{
Glenda M. López-Portillo ${ }^{1}$, Zain A. Sobani², Gulshan Parasher² and Sergio A. Sánchez-Luna ${ }^{3 *}$ \\ ${ }^{1}$ School of Medicine, Department of Internal Medicine, The University of New Mexico, Albuquerque, New Mexico; ${ }^{2}$ School of Medicine, Division of \\ Gastroenterology and Hepatology, The University of New Mexico, Albuquerque, New Mexico; ${ }^{3}$ Division of Gastroenterology, Hepatology and Nutrition, \\ Center for Advanced Therapeutic Endoscopy, Allegheny Center for Digestive Health, Pittsburgh. United States of America
}

\begin{abstract}
Non-sharp-pointed foreign bodies that partially obstruct the esophagus require urgent $(<24 h)$ endoscopic retrieval. In this briefcase report, we report an alternative method of retrieving an unusual foreign object.
\end{abstract}

Key words: Foreign object. Endoscopy. Upper gastrointestinal tract.

\section{¡Amárrate el cinturón!: extracción endoscópica de objetos extraños}

\section{Resumen}

Los cuerpos extraños no puntiagudos que obstruyen parcialmente el esófago requieren una recuperación endoscópica urgente (<24 horas). En este breve informe de caso, informamos un método alternativo para recuperar un objeto extraño inusual.

Palabras clave: Cuerpo extraño. Endoscopia. Tracto gastrointestinal superior.

\section{Introduction}

Non-sharp-pointed foreign bodies that partially obstruct the esophagus require urgent $(<24 \mathrm{~h}$ ) endoscopic retrieval. In this briefcase report, we report an alternative method of retrieving an unusual foreign object.

\section{Case report}

A 31-year-old female with bipolar disorder presented to our emergency department after the intentional ingestion of a belt buckle. Her only complaint was epigastric pain. A supine abdominal X-ray showed a buckle-shaped, radio-opaque foreign body projecting at the level of the diaphragm (Fig. 1A). Upper endoscopy under general anesthesia and intubation of the patient within $12 \mathrm{~h}$ of presentation revealed a partially obstructing belt buckle lodged in the distal esophagus (Fig. 1B). Due to esophageal spasm and difficulty grasping the buckle with the forceps, this was gently advanced into the stomach to allow for a better position to retrieve it from the bar of it to prevent the prong from opening up and causing damage in the stomach and esophageal 


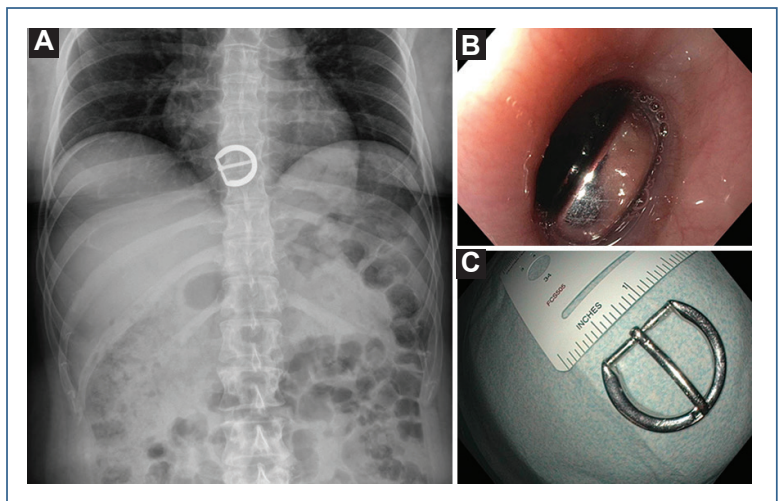

Figure 1. A: Chest $\mathrm{X}$-ray showing a foreign object projected at the level of the distal esophagus. B: Upper endoscopy (EGD) showing a belt buckle impacted in the distal esophagus. C: Status endoscopic removal of the belt buckle.

walls. Neither glucagon nor a latex rubber hood was used. Several attempts at grasping the bar of the buckle failed to ensure an adequate grasp of it, given the slippery surface of the metal. Nevertheless, once an adequate grasp was obtained with the forceps, the belt buckle was slowly retrieved from the esophagus while slowly performing minimal torquing of the endoscope to ensure that the trauma to the esophageal wall was minimal. The object measured 1.25 inches at its largest diameter (Fig. 1C). Reinsertion of the endoscope revealed only minimal erythema and scattered ecchymoses in the esophageal wall, but no mucosal tear or perforation was noted. The patient had no post-procedural complications and was discharged home 2 days after the initial presentation.

\section{Discussion}

Non-sharp-pointed foreign bodies that partially obstruct the esophagus require urgent ( $<24 \mathrm{~h}$ ) endoscopic retriev$\mathrm{al}^{1}$. Endoscopic retrieval of foreign bodies wider than 1 inch is preferred as these may be less likely to pass the pylorus $^{1,2}$. The push technique - whereas the foreign object is advanced into the stomach to facilitate retrieval - has been validated in the management of esophageal food bolus impactions in two large published series ${ }^{3,4}$. As in this case, with adequate visualization, the same technique may be applied to non-sharp-pointed foreign bodies lodged in the distal esophagus ${ }^{1}$. It is important to know that optimal evaluation of the foreign object to be retrieved, along with potentially dangerous parts of it (in our case, the prong of the buckle), is essential to allow for a safe and effective retrieval with the least possible damage to the surrounding structures.

Overtubes, latex rubber hoods, and clear caps can be used when faced with sharp-pointed objects to minimize injury to the esophageal and gastric walls ${ }^{2}$, but these tools have the limitation of not having enough capacity for bigger foreign objects like the one our patient had.

Although in our patient, we did not use glucagon to minimize esophageal peristalsis since this was not prominent, its use has been described in the literature as an aid for allowing esophageal food impactions to pass into the stomach ${ }^{2,5,6}$. Nevertheless, this has been shown to be effective only in one-third of the patients ${ }^{5}$ and in the absence of a fixed esophageal obstruction ${ }^{6}$. Furthermore, it can be used as an aid to decrease peristalsis to achieve better visualization and maneuverability of the endoscope during the extraction of foreign bodies. The use of glucagon should not delay definite endoscopic therapy, and its use is associated in some cases with nausea and emesis which can increase the risk of perforation ${ }^{2}$.

To the best of our knowledge, this is the first report of successful endoscopic retrieval of a belt buckle impacted in the distal esophagus.

\section{Conclusions}

In summary, esophageal foreign bodies are commonly encountered in practice. Optimal visualization and knowledge of the available tools for retrieval, alongside with the limitations of them, are key for successful retrieval and to avoid potential complications.

\section{Specific author contributions}

GM López-Portillo, Z Sobani, and SA Sánchez-Luna collected data and wrote the manuscript and revised the manuscript for intellectual content. SA Sánchez-Luna and G Parasher revised the manuscript for intellectual content and endoscopy imaging. SA Sánchez-Luna is the article guarantor. All authors involved in this report approved the final version.

\section{Conflicts of interest}

Gulshan Parasher, M.D., is a consultant for Boston Scientific, but this was not relevant to this manuscript. The rest of the authors declare no conflicts of interest.

\section{Funding}

None. 


\section{Ethical disclosures}

Protection of human and animal subjects. The authors declare that no experiments were performed on humans or animals for this study.

Confidentiality of data. The authors declare that they have followed the protocols of their work center on the publication of patient data.

Right to privacy and informed consent. The authors have obtained the written informed consent of the patients or subjects mentioned in the article. The corresponding author is in possession of this document.

\section{References}

1. ASGE Standards of Practice Committee, Ikenberry SO, Jue T, Anderson MA Appalaneni V, Banerjee S, Ben-Menachem T, et al. Management of ingested foreign bodies and food impactions. Gastrointest Endosc. 2011;73:1085-91.

2. Birk M, Bauerfeind P, Deprez PH, Häfner M, Hartmann D, Hassan C et al. Removal of foreign bodies in the upper gastrointestinal tract in adults: European society of gastrointestinal endoscopy (ESGE) clinical guideline. Endoscopy 2016;48:489-96.

3. Longstreth GF, Longatreth KJ, Yao JF. Esophageal food impaction: epidemiology and therapy. A retrospective, observational study. Gastrointest Endosc. 2001;53:193-8.

4. Vicari JJ, Johanson JF, Frakes JT. Outcomes of acute esophageal food impaction: success of the push technique Gastrointest Endosc. 2011:53:178-81

5. Al-Haddad M, Ward EM, Scolapio JS, Ferguson DD, Raimondo M. Glucagon for the relief of esophageal food impaction does it really work? Dig Dis Sci. 2006:51:1930-3.

6. Sodeman TC, Harewood GC, Baron TH. Assessment of the predictors of response to glucagon in the setting of acute esophageal food bolus impaction. Dysphagia. 2004;19:18-21. 